\title{
AN OVERVIEW OF DIFFERENT APPROACHES FOR SUSTAINABLE PRODUCTION AND CONVERTIBILITY OF HYDROXYMETHYLFURFURAL
}

\author{
Shamba Chatterjee ${ }^{1 *}$, Soumik Gangopadhyay ${ }^{2}$, Sayantan Patra ${ }^{2}$, Sayanta Pal Chowdhury ${ }^{3}$ \\ ${ }^{1}$ Assistant Professor, Department of Biotechnology, Haldia Institute of Technology, Haldia, India \\ *Corresponding Author: shambac@gmail.com \\ ${ }^{2}$ Student, Department of Mechanical Engineering, Haldia Institute of Technology, Haldia, India \\ ${ }^{3}$ Student, Department of Biotechnology, Haldia Institute of Technology, Haldia, India
}

\begin{abstract}
Reducing level of fossil fuel reserves and rising concerns regarding global warming unveils that sustainable resources of energy are required in the coming decades. Renewable liquid fuel is thus of utmost importance in the transportation sector and ethanol one of its kind currently suffers from various limitations as well as contamination following the absorption of water from the surrounding atmosphere. Nowadays, Hydroxymethylfurfural (HMF) is one of the most promising alternatives obtained from biomass due to its convertibility into a large number of chemicals having implications in different industries. It can be successfully produced from sustainable biomass feedstocks at low costs utilizing environment-friendly approaches. This brief introspection emphasizes several reaction systems to produce HMF from various substrates and their merits, demerits and requirements for sound commercialization.
\end{abstract}

Keywords: Hydroxymethylfurfural; Biomass; Biorefinery; Synthetic pathways

\section{INTRODUCTION}

In recent years, the rapidly growing prices of fossil fuels and concerns about the environmental consequences of greenhouse gas emissions have rejuvenated the concentration in the development of alternative energy resources. Biomass driven biorefineries are now becoming the new approach towards the replacement of fossil fuels driven present day petroleum refineries. Precisely saying a biorefinery will employ simple molecules that can be readily procured from a variety of feedstock as a start up for the synthesis of biopolymers and other large molecules $[1,2]$. Hydroxymethylfurfural (HMF) is one of the useful petroleum-derived chemical compound with immense potentiality that can be readily synthesized from renewable resources and holds stout position in the production of biomass-derived intermediates [3]. HMF can potentially be employed in fuel cells as well as in the treatment of sickle cell disease $[4,5]$ and its derivatives are also of utmost importance (Table 1) [6-11]. However, it plays as a principal platform chemical which in turn depends on its availability and cost [1215]. Researches are in progress to introspect whether HMF could be produced at reduced price in order to be utilized as a replacement for certain target compounds $[16,17]$. In recent times, one group stated that HMF manufactured at \$1210/ton would be cost competitive and also share that this price is attainable for a fructose price of $460 \$ /$ ton [18]. Thus, several approaches have been taken into account to explore the advantages and disadvantages of the diverse schemes involved, particularly with respect to the feedstocks employed, the yields achieved, and the associated environmental impacts.
This review, therefore, draws an overall portrait regarding the production of HMF from an array of carbohydrates and lignocellulosic biomass utilizing a variety of solvent and catalyst systems, and helps this building block to accomplish the desired level of commercialization.

\section{BACKGROUND OF HMF SYNTHESIS}

Hydroxymethylfurfural (HMF) is a yellow low-melting solid and having solubility in a range of solvents, viz., water, methanol, ethanol, benzene, acetone, chloroform, formaldehyde and ethyl acetate [19]. It consists of a furan ring, containing both aldehyde and alcohol functional groups. The HMF molecule with an odor of chamomile flowers possesses a boiling point between 114 and $116^{\circ} \mathrm{C}$ and a density of 1.2062 $\mathrm{g} / \mathrm{cc}$ at $25^{\circ} \mathrm{C}[12,13,19,21]$. It is generally produced by the acid catalysis of a hexose material resulting in loss of three molecules of water [35] and in this process several side reactions including the re-hydration of the hydroxymethylfurfural to levulinic acid and formic acid, and cross-polymerization to soluble polymers and insoluble humins also is of utmost importance [20, 22]. Several mechanisms are involved in the formation of HMF from fructose by acyclic (Fig. 1) and cyclic pathway (Fig. 2). Some groups followed the cyclic route concerning a fructofuranosyl cationic intermediate and others nodded towards the acyclic route involving an enediol intermediate [22-26]. Researchers have also pointed out that HMF synthesis is relatively more efficient and selective from fructose than from glucose [20, 27, 28]. In case of sucrose as starting material the acid-catalysed hydrolysis produces the fructofuranosyl ion and glucose, where the 
previous one acting as the principal intermediate for the formation of HMF [26]. The reversible Lobryede Bruynevan Ekenstein transformation thus serves as an important hub for the interconversion of glucose and fructose in the synthesis of HMF [28].

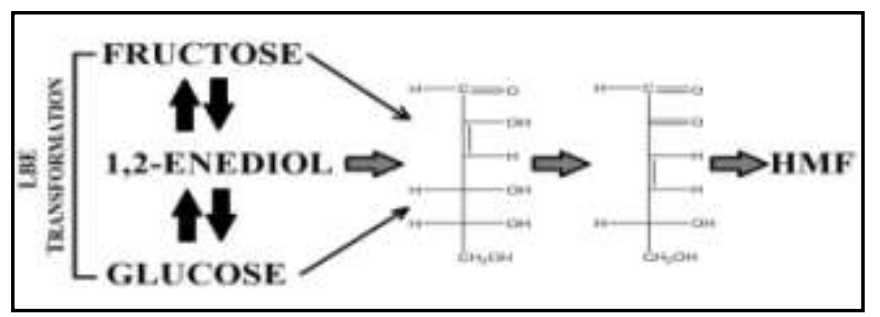

Fig. 1: Acyclic route for HMF synthesis

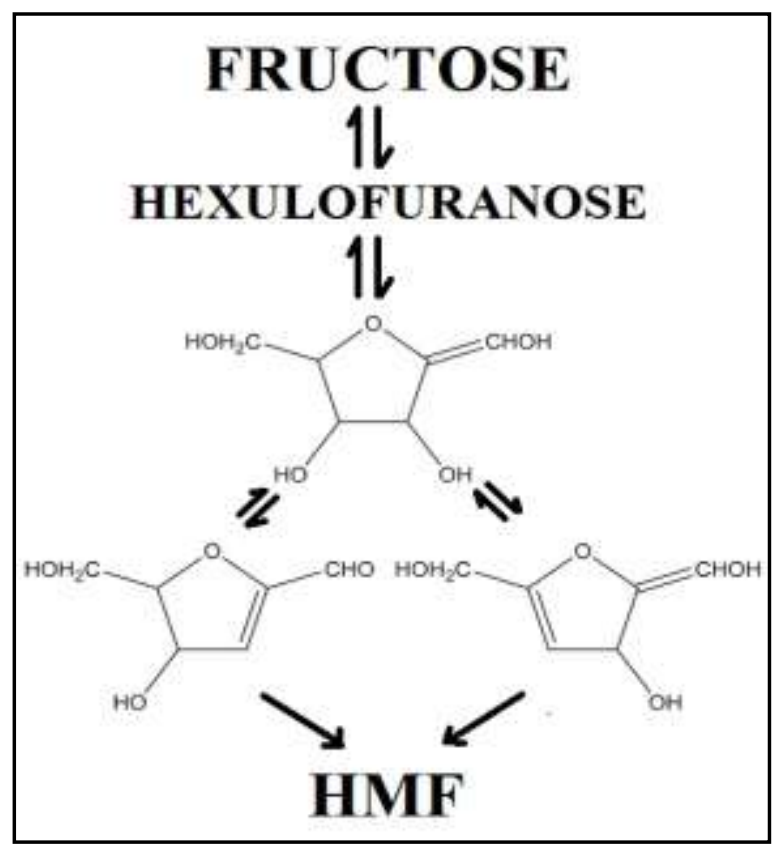

Fig. 2: Cyclic route for HMF synthesis

\section{FEEDSTOCK}

Researchers mainly concentrate on the hexose sugars fructose and glucose as the starting point for HMF synthesis. Amongst them, fructose is comparatively easier to convert into HMF than glucose, but the latter has been regarded as better one for its sound availability [29]. However, glucose can be isomerized into fructose following the use of some catalysts (e.g. $\mathrm{TiO}_{2}$ and $\mathrm{ZrO}_{2}$ ) [30]. Alternatively, incorporation of an immobilized glucose isomerase enzyme alleviates the conversion of glucose to fructose and subsequent conversion to $\mathrm{HMF}$ in presence of an acid catalyst [31]. Recent findings have unveiled a number of polysaccharides as potential feedstock, viz., starch [32], cellulose [33], chitin [34] and inulin [35]. The only major step that has to be taken before their potential implication is to depolymerise them through hydrolysis before the dehydration of the monomers into HMF [36]. On the other hand, lignocellulosic biomass is also of utmost importance regarding HMF production [37]. It comprises of cellulose (38-50\%), hemicellulose (23-32\%) and lignin (15-25\%), along with some amount of organic substances and inorganic ashes, but the exact composition varies depending on the source [38, 39].
Precisely saying, the cellulose and hemicellulosic contents in lignocellulose are composed of hexoses that in turn produce HMF by dehydration process [36]. Some researchers have preferred to separate these two components before processing and others nodded towards integrated conversion processes $[37,40]$. Above all, polysaccharides and raw biomass are the feedstock that is commercially preferred over monosaccharides following their economic aspects.

\section{REACTION SYSTEMS}

Several approaches have been introspected for the sound synthesis of HMF from an array of different feedstocks. There are certain features that one has to concentrate for suitable yield. Mainly, they are based either on the catalyst employed or on the solvent nature (e.g. protic and aprotic). Current researchers have also emphasized on the microwave heating systems for suitable outcome.

\subsection{CATALYSTS EMPLOYED}

Even if catalytic production of HMF are popular over noncatalytic production, but the latter can be achieved through the implication of high temperature, pressure and prolonged reaction times $[41,42]$.

A range of inorganic and organic acidic compounds are available that can potentially catalyze $\mathrm{HMF}$ synthesis whereas mineral acids (e.g. $\mathrm{H}_{2} \mathrm{SO}_{4}, \mathrm{H}_{3} \mathrm{PO}_{4}, \mathrm{HCl}$ ) are extensively used following their low cost, high yield and easy availability [62]. However, a combination of weak acid and weak base as catalysts works better than acid catalysts alone. An investigation revealed that hydrothermal conversion of cellulose to HMF resulted in highest yield in acidic and lowest in alkaline conditions, whereas in case of purity concern, the order was neutral, acidic and alkaline conditions [43]. Earlier concept had supported that merely strong Brønsted acids like $\mathrm{H}_{2} \mathrm{SO}_{4}$ can catalyze the reaction [26], but recent approach unveiled that levulinic acid (LA) and formic acid cannot autocatalyze the production of HMF, LA or formic acid from glucose [44]. It is well versed that HMF is an intermediary in the formation of LA from biomass, and following this reason liquid acid catalysts have also been utilized to manufacture LA. In this context, $\mathrm{HCl}$ is the foremost one for converting various carbohydrate-containing materials like wood tailings to LA by vacuum distillation as it can be recovered and recycled without difficulty [45].

Additionally, solid catalysts have gained attention for HMF manufacture by the use of aluminium sulphate and aluminium chloride as catalysts in 1969 [46]. They are industrially preferable over liquid ones due to the reasons as follows: (i) easily separable and recyclable, (ii) sustainable at higher temperatures, (iii) short reaction time and overall their (iv) adjustable surface acidity resulting in enhanced selectivity [47, 48]. Some of the reported ones are $\mathrm{SO}_{4}{ }^{2-} / \mathrm{ZrO}_{2}-\mathrm{Al}_{2} \mathrm{O}_{3}$, zirconium phosphate, ion-exchange resins, zirconia/titania, stannous/stannic chloride, $\mathrm{AlCl}_{3} \cdot 6 \mathrm{H}_{2} \mathrm{O}, \mathrm{Sn}$-Mont [32, 48, 49, $50,51,52]$. However, a few reaction byproducts such as coke and humin may reduce their catalytic efficiency, but calcining them at high temperatures $\left(400-500{ }^{\circ} \mathrm{C}\right)$ for prolonged period 
rejuvenates catalytic action [53-56]. On the other hand, temperature sensitive solid catalysts can be recovered by using washing reagents like $\mathrm{NaOH}[48], \mathrm{H}_{2} \mathrm{O}_{2}$ [54, 57], $\mathrm{HCl}[58,59]$, $\mathrm{C}_{2} \mathrm{H}_{5} \mathrm{OH}$ [59], $\mathrm{CH}_{3} \mathrm{OH}$ [60], $\left(\mathrm{CH}_{3}\right)_{2} \mathrm{CO}$ [61], etc. Some solid catalysts like lanthanide, zirconium, titanium, niobium, organic-inorganic nanocomposite (polyvinylpyrrolidone intercalated into the pores of silica) based catalysts, etc. have shown higher selectivity in HMF production [62-66]. The toxicity and cost aspect is also of utmost importance [67-71].

\subsection{SOLVENTS EMPLOYED}

Various solvents have been used for the synthesis of HMF and their suitability varies in terms of substrate conversion, product selectivity as well as yields, and above all the environmental impact of these solvents [72]. Following this, water is the prime choice to be used as protic solvents, due to its ubiquity, physical and chemical characteristics, and eco-friendly nature. Butanol is extremely effective as an organic co-solvent in biphasic mixtures and can be utilized as sole solvent or in conjunction with water (e.g. 1-butanol, 2-butanol and isobutanol) [73-75]. Several other polar aprotic solvents are commonly used for HMF as well as LA synthesis, such as DMSO, dimethylformamide (DMF), dimethylacetamide (DMA), tetrahydrofuran (THF) and ethyl acetate. Here, DMSO is the foremost one regarding HMF synthesis as it suppresses the hydrolysis of HMF to LA and formic acid except the large energy requirement for its separation from the final product as well as the trend of toxic sulphur-containing by-products build up during the process [76-79]. On the other hand, THF, is less favoured due to its high cost and adverse environmental effects [80]. In this context, the use of novel environment-friendly aprotic solvents has drawn immense attention.

N-methylpyrrolidone) [81].

A bi-phasic mixture is often popular for the instant removal of HMF from the reaction mixture during its formation. An immiscible organic phase with a higher partition coefficient for HMF is thus useful for its sound recovery from the organic phase [81]. One can employ methyl isobutyl ketone, dichloromethane and 2-butanol as such extracting solvents.

Further, ionic liquids are also employed in HMF synthesis and are well-appreciated due to its stability, low vapour pressure, recyclability, as well as their readily moderable physical and chemical properties by varying the ions $[47,82]$. Besides this, they can be chosen over conventional solvents following their ability to convert raw biomass directly into the final products [83-85]. Moreover, they have the ability to act as catalysts along with their solvation capability [86-88]. The most significant ones are 1-butyl-3-methylimidazolium $\left([\mathrm{BMIM}]^{+}\right)$, 1-ethyl-3-methylimidazolium $\quad\left([\mathrm{EMIM}]^{+}\right), \quad$ 1-octyl-3methylimidazolium ([OMIM $]^{+}$), 1-hexyl-3-methylimidazolium [HMIM] etc. [82, 89]. Though they are popular as solvents, but the production methodology of the ionic liquid and its toxic properties are still under query regarding environmental aspects [90]. Additionally, they have some negative characteristics like High cost, poor transport properties, extreme corrosivity in the presence of water, and low vapour pressure preventing recovery of used ones via distillation [9195]. Thus, solvent extraction method or adsorption through zeolite column can be explored for better recovery of the ionic liquid [18, 87, 96-99]. On the other hand, vacuum reactive distillation is usefull for efficient separation of HMF from the ionic liquid [100].

\subsection{ADDITIVES EMPLOYED}

Several additives such as $\mathrm{NaCl}$ enhance the partitioning coefficient between tetrahydrofuran (THF) and water and avert HMF from getting dehydrated to LA [52]. Sometimes, it may also be useful when microwave irradiation is utilized for heating, especially if water acted as the solvent [101].

\section{LABORATORY, PILOT AND COMMERCIAL- SCALE PRODUCTION OF HMF}

Several studies have unveiled different reaction conditions for the laboratory-scale production of HMF from a range of feedstocks. The following significant facts are summarized regarding the above:

- Their activity in carbohydrate dehydration in ionic liquids as the dissociation constants of them in ionic liquids is generally unidentified [111].

- Some researchers have also discovered In case of liquid catalysts, low $\mathrm{pH}$ values alleviate the conversion of fructose to HMF with higher yields. Additionally, different acids provide different outcome for the same $\mathrm{pH}$ value and the success rate is as follows: $\mathrm{HCl}>\mathrm{H}_{2} \mathrm{SO}_{4}>\mathrm{H}_{3} \mathrm{PO}_{4}$. Organic acids perform in an inferior manner even at high concentrations.

- The implication of a co-solvent system like methyl isobutyl ketone with water augments HMF yield $(\sim 50 \%)$. This corroborates the concept depicted in earlier section about extracting solvents raising HMF yields by lowering its rehydration.

- Laboratory-scale outcomes exposed that ion exchange resins as solid catalysts facilitate the reaction at relatively low temperatures with high HMF yields $(\sim 50 \%)$.

- Once niobium phosphate has been employed as solid acid catalysts, its deactivation occur at a very fast rate following the deposition of insoluble humins or coke onto it that in turn enhance HMF selectivity with increased fructose conversion [102].

- One can achieve the maximum wt (\%) yield $(\sim 70 \%)$ by using some solvent-catalyst systems like DMSO:Borontrifluoride-etherate, THF-DMSO:glucoseTsOH, DMSO: $\mathrm{H}_{3} \mathrm{PW}_{12} \mathrm{O}_{40}$ and secbutanol:[MIMPS $]_{3} \mathrm{PW}_{12} \mathrm{O}_{40}$.

- The most convincing systems at high fructose concentrations with significant $\mathrm{HMF}$ yields are waterMIBK: $\mathrm{B}(\mathrm{OH})_{3}-\mathrm{MgCl}_{2}$, and water-DMSO-MIBKbutanol:HCl.

- Interestingly, HMF yields from monosaccharides other than fructose are significantly lower than those achieved from fructose. This emphasizes the use of a catalytic system that eases the isomerization of monosaccharides, mostly glucose, into fructose (e.g. $\mathrm{CrBr}_{3}$ and $\mathrm{LiBr}$ as catalysts in DMA solvent) [103]. Whereas, Psicose has a high furanose propensity like fructose, and thus can readily be converted to HMF [104]. If one employs sorbose as a substrate the 
triethylene glycol-water: $\mathrm{HCl}$ system provides remarkable yield upto $47 \%$.

- On the other hand, HMF yields attained from polysaccharides are considerably poorer than those procured from monosaccharides, especially fructose. Here, inulin serves for the highest yield $[63,81,105]$ and starch as well as cellulose provides the same in case of biphasic solvent systems with solid catalysts $[80,106]$.

- High HMF yields are achieved from most feedstock at comparatively low temperatures and short reaction times by the implication of ionic liquids. One of the revolutionary works in this regard employed $\mathrm{CrCl}_{2}$ as catalyst in [EMIM]Cl to obtain high yields $(\sim 70 \%)$ from glucose [107]. They are also efficient in converting polysaccharides to HMF. For example, an [EMIM]Cl-based system can reach nearly $70 \% \mathrm{HMF}$ yield from cellulose [108]. It is noteworthy that $[\mathrm{BMIM}] \mathrm{Cl}$ and $[\mathrm{EMIM}] \mathrm{Cl}$ provide higher HMF output when chromium-based catalysts are utilized than ionic liquids containing more bulky cations like [BEMIM]Cl, [HEMIM]Cl and [OMIM]Cl [109, 110]. On the other hand, while liquid acids are employed as catalysts, it is hard to forecast that pre-treated raw biomass like jerusalem artichoke and chicory roots, which are rich in inulin, can directly be converted to HMF. Additionally, the use of the ionic liquid [OMIM]Cl and $\mathrm{CrF}_{3}$ catalyst offers astonishingly high HMF yields from the starch rich tapioca roots [112].

In an assorted manner, one can summarize that fructose is the most convenient and popular feedstock regarding high yields and is therefore the foremost choice for researchers introspecting novel reaction systems. In case of polysaccharides, inulin, is fairly promising with high yields, while sound yields can be procured from other polysaccharides utilizing biphasic solvent systems and/or particular solid catalysts. Others like raw biomass, ionic liquids give much higher yields, especially in conjugation with catalysts like $\mathrm{CrCl}_{3}$.

In spite of the vast importance of HMF and the number of reaction schemes developed, still we don't have any fully phased commercial units for HMF production in mass scale and only a small number of pilot processes have been reported. The earliest report in this regard has shown a distilled HMF yield of up to $63 \%$ from a sucrose solution (50 wt $\%$ ) which requires a time period of more than $9 \mathrm{~h}$ [113]. Next, Südzucker AG devised a scheme for the production of HMF from fructose and inulin with oxalic acid as catalyst followed by the purification through column chromatography [114]. Another group used cationic resins in a water-methyl isobutyl ketone (MIBK) system with $38 \% \mathrm{HMF}$ yield by fructose dehydration [114, 115]. Additionally, a non-catalytic process employing DMSO as solvent, has shown 85\% HMF yield after being extracted in a counter-current column using dichloromethane (DCM) [12, 116]. Above all, mammoth techno-economical improvements have to be made for commercial scale manufacturing of HMF with sufficient purity which in turn demands the entire separation and appropriate removal of the by-products.

\section{MICROWAVE HEATING SYSTEMS FOR HMF SYNTHESIS: A BRIEF UNDERSTANDING}

Microwave heating has drawn extreme importance as a heating method for synthetic transformations due to its sound role in remarkable enhancement in reaction rates and yields $[41,117$, 118]. Some of the advantageous characteristics of this system include:

- It provides more homogeneous heat distribution and less side-wall effects than conventional heating [28].

- One can potentially control reaction parameters and decide which reaction solvent is to be employed [119].

- Additionally, its selective approach helps polar substances to be heated rapidly, while non-polar substances are not heated that in turn amend the selectivity of a reaction or keep away from decomposition of thermally unstable species [120].

- Conversely, non-polar solvents can still be used if a small amount of inert polar solvent is added [121].

- Above all, it may also be more energy efficient than conventional methods of heating [122, 123].

All of the above mentioned advantages of microwave heating have made us curious to introspect the possibility of using this system for producing HMF and other chemicals from cellulose and lignocellulosic biomass. Some of the remarkable works on HMF synthesis using microwave irradiation in recent years are as follows:

- Minimum by-product formation can be achieved for HMF production in aqueous media by enhancement of initial fructose concentration as well as reduction in $\mathrm{HCl}$ catalyst level [41].

- The hydrothermal conversion of glucose and fructose under microwave irradiation revealed that the decomposition of glucose requires higher temperatures than fructose. The maximum HMF yield from fructose and glucose were $47 \%$ and $29.5 \%$ respectively [28].

- When cellulose and glucose were employed to produce $\mathrm{HMF}$ in the ionic liquid [BMIM] Cl using $\mathrm{CrCl}_{3}$ catalyst, the yields were around $60 \%$ and $90 \%$ respectively [124]. The same system achieved a HMF yield of up to $52 \%$ by using lignocellulosic biomass like corn stalk, rice straw and pine wood [125]. Interestingly, $\mathrm{ZrCl}_{4}$ was the most effective catalyst regarding HMF yield [126]. In addition, one research outcome supported that cellulose can directly be converted to $\mathrm{HMF}$ via reusable $\mathrm{ZnCl}_{4}$-[BMIM]Cl system with a maximum yield of around 50\%. Whereas, HMF from cellulose and wheat straw can also be obtained by using microwave irradiation and [BMIM]Cl along with $\mathrm{CrCl}_{3} / \mathrm{LiCl}$ [83].

- Another work revealed when fructose, glucose, sucrose, starch and inulin were used as the substrates along with water, water/MIBK or DMSO as the solvent, the HMF yields obtained by microwave heating was as high as $71 \%$ [127].

- Direct conversion of a number of weeds to HMF using microwave heating has also been tried successfully with 
Brønsted acidic ionic liquid and silica supported immobilized heteropolyacid (HPA) catalysts [128].

- Researchers have also noted that microwave irradiation can successfully convert fructose to HMF by using an acidic cation exchange resin (Dowex 50wx8-100) in a mixed organic-aqueous system [129].

The examples presented above clearly demonstrates the utility of microwave heating for synthesizing HMF with high yields from a variety of feedstock and thus emphasizes the future need towards developing pilot scale reactors utilizing it.

\section{CONCLUSIONS}

The prospect of potential research activity in the chemistry of 5-hydroxymethylfurfural (HMF) prompted the vision of this brief review. HMF itself is an attractive raw material following its high reactivity and above all the multi-functionality as it is simultaneously a primary aromatic alcohol, an aromatic aldehyde and a furan ring system. Till date, derivatives of HMF have already been employed in agrochemistry as fungicides, in galvanochemistry as corrosion inhibitors, in cosmetic industry as flavour agents and as an excellent prime candidate for the synthesis of precursors of different pharmaceuticals, thermo-resistant polymers and complex macrocycles. The successful commercialization of HMF needs its cost-effective synthesis approach with high yield from a variety of biomass feedstocks having nominal environmental effect. Furthermore, researches on modified isolation techniques are also necessary to obtain highly pure products. Thus, studies on HMF and its derivatives will be continued with utmost interest.

\section{ACKNOWLEDGEMENT}

The authors are grateful to the home institute for providing space and resources to carry out this work.

\section{REFERENCES}

[1] T. Werpy and G. Petersen, "Top value added chemicals from biomass," Pacific Northwest National Laboratory, National Renewable Energy Laboratory, 2004.

[2] R. Rajagopal, "Bio-based chemicals: In need of innovative strategies," IGCW 2011, Mumbai, 2011.

[3] M. Bicker, D. Kaiser, L. Ott and H. Vogel, "Dehydration of D-fructose to hydroxymethylfurfural in sub- and supercritical fluids," J Supercrit Fluids, vol. 36, pp. 118, 2005.

[4] J.P. Breen, "The effects of temperature and working electrode material on the power output of a hydroxymethylfurfural fuel cell," Chemical Engineering, Oregon State University, 2013.

[5] O. Abdulmalik, M.K. Safo, Q. Chen, J. Yang, C. Brugnara, $\mathrm{K}$. Ohene-Frempong, et al. "5-Hydroxymethyl-2-furfural modifies intracellular sickle haemoglobin and inhibits sickling of red blood cells," Br J Haematol, vol. 128, pp. 552, 2005.

[6] Z.Z. Yang, J. Deng, T. Pan, Q.X. Guo and Y. Fu, "A onepot approach for conversion of fructose to 2,5-diformylfuran by combination of $\mathrm{Fe}_{3} \mathrm{O}_{4}-\mathrm{SBA}-\mathrm{SO}_{3} \mathrm{H}$ and K-OMS-2," Green Chem, vol. 14, pp. 2986, 2012.

[7] Y. Roman-Leshkov, C.J. Barrett, Z.Y. Liu and J.A. Dumesic, "Production of dimethylfuran for liquid fuels from biomass derived carbohydrates," Nature, vol. 447, pp. 982, 2007.

[8] G. Li, N. Li, S. Li, A. Wang, Y. Cong, X. Wang, et al. "Synthesis of renewable diesel with hydroxyacetone and 2methyl-furan," Chem Commun, vol. 49, pp. 5727, 2013.

[9] D. Hayes, J. Ross, M.H.B. Hayes and S. Fitzpatrick, "The biofine process-production of levulinic acid, furfural and formic acid from lignocellulosic feedstock," In: Kamm B, Gruber P, Kamm M, editors. Biorefineries e industrial processes and products, Weinheim: Wiley-VCH, p. 139, 2006.

[10] C. Moreau, M.N. Belgacem and A. Gandini, "Recent catalytic advances in the chemistry of substituted furans from carbohydrates and in the ensuing polymers," Top Catal, vol. 27, pp.11, 2004.

[11] M. Zakrzewska, E. Bogel-Łukasik and R. Bogel-Łukasik, "Ionic liquid-mediated formation of 5-hydroxymethylfurfural a promising biomass-derived building block," Chem Rev, vol. 111, pp. 397, 2011.

[12] R.J. van Putten, J.C .van der Waal, E. de Jong, C.B. Rasrendra, H.J. Heeres and J.G. de Vries, "Hydroxymethylfurfural, a versatile platform chemical made from renewable resources," Chem Rev, vol. 113, pp. 1499, 2013.

[13] M. Kunz, "Hydroxymethylfurfural, a possible basic chemical for industrial intermediates," In: Fuchs A, editor. Inulin and inulin-containing crops, Amsterdam: Elsevier, p. 149, 1993.

[14] F.W. Lichtenthaler, "Unsaturated O- and N-heterocycles from carbohydrate feedstocks," Acc Chem Res, vol. 35, pp.728, 2002.

[15] M. Bicker, J. Hirth and H. Vogel, "Dehydration of fructose to 5-hydroxymethylfurfural in sub- and supercritical acetone," Green Chem, vol. 5, pp. 280, 2003.

[16] A.I. Torres, P. Daoutidis and M. Tsapatsis, "Continuous production of 5-hydroxymethylfurfural from fructose: a design case study," Energy Environ Sci, vol. 3, pp. 1560, 2010.

[17] F.K. Kazi, A.D. Patel, J.C. Serrano-Ruiz, J.A. Dumesic and R.P. Anex, "Techno-economic analysis of dimethylfuran (DMF) and hydroxymethylfurfural (HMF) production from pure fructose in catalytic processes," Chem Eng J, vol. 169, pp. 329, 2011.

[18] W. Liu, F. Richard Zheng, J. Li and A. Cooper, "An ionic liquid reaction and separation process for production of hydroxymethylfurfural from sugars," AIChE J, vol. 60, pp. 300, 2013.

[19] PubChem, Open Chemistry Database: Compound Summary for CID 237332, 5-Hydroxymethylfurfural, 2015.

[20] J. Lewkowski, "Synthesis, chemistry and applications of 5-hydroxymethylfurfural and its derivatives," Arkivoc, vol. 2001, pp. 17, 2001.

[21] S. Kowalski, M. Lukasiewicz, A. Duda-Chodak and G. Zięć, "5-hydroxymethyl-2-furfural (HMF) - heat-induced formation, occurrence in food and biotransformation - a review," Pol J Food Nutr Sci, vol. 63, pp. 207, 2013.

[22] B.F.M. Kuster, "5-Hydroxymethylfurfural (HMF) - a review focussing on its manufacture," Starch-Stärke, vol. 42, pp.314, 1990.

[23] W. Haworth and W. Jones, "The conversion of sucrose into furan compounds part 1: 5-hydroxymethylfurfuraldehyde and some derivatives," J Chem Soc, pp. 667, 1944.

[24] M.L. Mednick, "The acidebase-catalyzed conversion of aldohexose into 5-(hydroxymethyl)-2-furfural," J Org Chem, vol. 27, pp. 398, 1962.

[25] M.L. Wolfrom, R.D. Schuetz and L.F. Cavalieri, "Chemical interactions of amino compounds and sugars III: the conversion of D-glucose to 5-(hydroxymethyl)-2-furaldehyde," J Am Chem Soc, vol. 70, pp. 514, 1948. 
[26] M. Antal, W. Mok and G. Richards, "Mechanism of formation of 5-(hydroxymethyl)-2-furaldehyde from Dfructose and sucrose," Carbohydr Res, vol. 199, pp. 91, 1990.

[27] A. Corma, S. Iborra and A. Velty, "Chemical routes for the transformation of biomass into chemicals," Chem Rev, vol. 107, pp. 2411, 2007.

[28] M. Möller, F. Harnisch and U. Schröder, "Microwaveassisted hydrothermal degradation of fructose and glucose in subcritical water," Biomass Bioenergy, vol. 39, pp. 389, 2012.

[29] X. Qi, M. Watanabe, T.M. Aida and R.L. Smith, "Synergistic conversion of glucose into 5hydroxymethylfurfural in ionic liquid-water mixtures," Bioresour Technol, vol. 109, pp. 224, 2012.

[30] X. Qi, M. Watanabe, T.M. Aida and R.L. Smith Jr., "Catalytical conversion of fructose and glucose into 5hydroxymethylfurfural in hot compressed water by microwave heating," Catal Commun, vol. 9, pp. 2244, 2008.

[31] R. Huang, W. Qi, R. Su and Z. He, "Integrating enzymatic and acid catalysis to convert glucose into 5hydroxymethylfurfural," Chem Commun, vol. 46, pp.1115, 2010.

[32] Y. Yang, X. Xiang, D. Tong, C. Hu and M.M. Abu-Omar, "One-pot synthesis of 5-hydroxymethylfurfural directly from starch over $\mathrm{SO}_{4}{ }^{2-} / \mathrm{ZrO}_{2}-\mathrm{Al}_{2} \mathrm{O}_{3}$ solid catalyst," Bioresour Technol, vol. 116, pp. 302, 2012.

[33] M. Mascal and E.B. Nikitin, "Direct, high-yield conversion of cellulose into biofuel," Angew Chem Int Ed Engl, vol. 47, pp.7924, 2008.

[34] K.W. Omari, J.E. Besaw and F.M. Kerton, "Hydrolysis of chitosan to yield levulinic acid and 5-hydroxymethylfurfural in water under microwave irradiation," Green Chem, vol. 14, pp. 1480, 2012.

[35] X. Qi, M. Watanabe, T.M. Aida and R.L. Smith Jr., "Efficient one-pot production of 5-hydroxymethylfurfural from inulin in ionic liquids," Green Chem, vol. 12, pp. 1855, 2010.

[36] A.A. Rosatella, S.P. Simeonov, R.F.M. Frade and C.A.M. Afonso, "5-Hydroxymethylfurfural (HMF) as a building block platform: biological properties, synthesis and synthetic applications," Green Chem, vol. 13, pp. 754, 2011.

[37] S. Dutta, S. De, M.I. Alam, M.M. Abu-Omar and B. Saha, "Direct conversion of cellulose and lignocellulosic biomass into chemicals and biofuel with metal chloride catalysts," $J$ Catal, vol. 288, pp. 8, 2012.

[38] B. Kamm, M. Gerhardt and G. Dautzenberg, "Catalytic processes of lignocellulosic feedstock conversion for production of furfural, levulinic acid, and formic acid-based fuel components," In: Suib SL, editor. New and future developments in catalysis: catalytic biomass conversion, p. 91, 2013.

[39] D.W. Rackemann and W.O.S. Doherty, "The conversion of lignocellulosics to levulinic acid," Biofuels Bioprod Biorefin, vol. 5, pp.198, 2011.

[40] D.M. Alonso, S.G. Wettstein, M.A. Mellmer, E.I. Gurbuz and J.A. Dumesic, "Integrated conversion of hemicellulose and cellulose from lignocellulosic biomass," Energy Environ Sci, vol. 6, pp. 76, 2013.

[41] T.S. Hansen, J.M. Woodley and A. Riisager, "Efficient microwave assisted synthesis of 5-hydroxymethylfurfural from concentrated aqueous fructose," Carbohydr Res, vol. 344, pp. 2568, 2009.

[42] Q. Jing and X Lü, "Kinetics of non-catalyzed decomposition of glucose in high-temperature liquid water," Chin J Chem Eng, vol. 16, pp. 890, 2008.

[43] S. Yin, Y. Pan and Z. Tan, "Hydrothermal conversion of cellulose to 5-hydroxymethyl furfural," Int J Green Energy, vol. 8, pp. 234, 2011.
[44] B. Girisuta, "Levulinic acid from lignocellulosic biomass" Chemical Engineering, University of Groningen, 2007.

[45] L.J. Carlson, United States patent 3,065,263. In: Office USPaT. United States of America: Rayonier Incorporated, 1962.

[46] J.D. Garber and R.E. Jones. United States patent 3,483,228. In: Office USPaT. United States of America: Merck \& Co., Inc.; 1969.

[47] X. Tong, Y. Ma and Y. Li, "Biomass into chemicals: conversion of sugars to furan derivatives by catalytic processes," Appl Catal A: Gen, vol. 385, pp. 1, 2010.

[48] R. Weingarten, W.C. Conner and G.W. Huber, "Production of levulinic acid from cellulose by hydrothermal decomposition combined with aqueous phase dehydration with a solid acid catalyst," Energy Environ Sci, vol. 5, pp. 7559, 2012.

[49] C.V. McNeff, D.T. Nowlan, L.C. McNeff, B. Yan and R.L. Fedie, "Continuous production of 5hydroxymethylfurfural from simple and complex carbohydrates," Appl Catal A: Gen, vol. 384, pp. 65, 2010.

[50] G. Tian, X. Tong, Y. Cheng and S. Xue, "Tin-catalyzed efficient conversion of carbohydrates for the production of 5hydroxymethylfurfural in the presence of quaternary ammonium salts," Carbohydr Res, vol. 370, pp. 33, 2013.

[51] Y. Yang, C-w Hu, M.M. Abu-Omar, "Conversion of carbohydrates and lignocellulosic biomass into 5hydroxymethylfurfural using $\mathrm{AlCl}_{3} \cdot 6 \mathrm{H}_{2} \mathrm{O}$ catalyst in a biphasic solvent system," Green Chem, vol. 14, pp. 509, 2012.

[52] J. Wang, J. Ren, X. Liu, J. Xi, Q. Xia, Y. Zu, et al. "Direct conversion of carbohydrates to 5-hydroxymethylfurfural using Sn-Mont catalyst," Green Chem, vol. 14, pp. 2506, 2012.

[53] A.M. Hengne and C.V. Rode, "Cu- $\mathrm{ZrO}_{2}$ nanocomposite catalyst for selective hydrogenation of levulinic acid and its ester to gvalerolactone," Green Chem, vol. 14, pp. 1064, 2012.

[54] D.M. Alonso, J.M.R. Gallo, M.A. Mellmer, S.G. Wettstein and J.A. Dumesic, "Direct conversion of cellulose to levulinic acid and gamma-valerolactone using solid acid catalysts," Catal Sci Technol, vol. 3, pp. 927, 2013.

[55] Y. Zhang, J. Wang, J. Ren, X. Liu, X. Li, Y. Xia, et al. "Mesoporous niobium phosphate: an excellent solid acid for the dehydration of fructose to 5-hydroxymethylfurfural in water," Catal Sci Technol, vol. 2, pp. 2485, 2012.

[56] S.S. Joshi, A.D. Zodge, K.V. Pandare and B.D. Kulkarni, "Efficient conversion of cellulose to levulinic acid by hydrothermal treatment using zirconium dioxide as a recyclable solid acid catalyst," Ind Eng Chem Res, vol. 53, pp. 11629, 2014.

[57] Y. Zuo, Y. Zhang and Y. Fu, "Catalytic conversion of cellulose into levulinic acid by a sulfonated chloromethyl polystyrene solid acid catalyst," Chem Cat Chem, vol. 6, pp. $753,2014$.

[58] B. Kim, C.A. Antonyraj, Y.J. Kim, B. Kim, S. Shin, S. Kim, et al. "Facile production of 5-hydroxymethyl-2-furfural from industrially supplied fructose syrup using a wood powder-derived carbon catalyst in an ethylene glycol-based solvent," Ind Eng Chem Res, vol. 53, pp. 4633, 2014.

[59] C. Tian, Y. Oyola, K.M. Nelson, S.H. Chai, X. Zhu, J.C. Bauer, et al. "A renewable $\mathrm{HSO}_{3} / \mathrm{H}_{2} \mathrm{PO}_{3}$-grafted polyethylene fiber catalyst: an efficient heterogeneous catalyst for the synthesis of 5-hydroxymethylfurfural from fructose in water," RSC Adv, vol. 3, pp. 21242, 2013.

[60] K.B. Sidhpuria, A.L. Daniel-da-Silva, T. Trindade and J.A.P. Coutinho, "Supported ionic liquid silica nanoparticles (SILnPs) as an efficient and recyclable heterogeneous catalyst for the dehydration of fructose to 5-hydroxymethylfurfural," Green Chem, vol. 13, pp. 340, 2011. 
[61] V. Heguaburu, J. Franco, L. Reina, C. Tabarez, G. Moyna and P. Moyna, "Dehydration of carbohydrates to 2furaldehydes in ionic liquids by catalysis with ion exchange resins," Catal Commun, vol. 27, pp. 88, 2012.

[62] K-i. Seri, Y. Inoue, and H. Ishida, "Catalytic activity of lanthanide(III) ions for the dehydration of hexose to 5Hydroxymethyl-2-furaldehyde in water," Bull Chem Soc Jpn, vol. 74, pp. 1145, 2001.

[63] F. Benvenuti, C. Carlini, P. Patrono, A.M.R. Galletti, G. Sbrana, M.A. Massucci, et al. "Heterogeneous zirconium and titanium catalysts for the selective synthesis of 5hydroxymethyl-2-furaldehyde from carbohydrates," Appl Catal A: Gen, vol. 193, pp. 147, 2000.

[64] C. Carlini, M. Giuttari, A.M.R. Galletti, G. Sbrana, T. Armaroli and G. Busca, "Selective saccharides dehydration to 5-hydroxymethyl-2-furaldehyde by heterogeneous niobium catalysts," Appl Catal A: Gen, vol. 183, pp. 295, 1999.

[65] R. Alamillo, A.J. Crisci, J.M. Gallo, S.L. Scott and J.A. Dumesic, "A tailored microenvironment for catalytic biomass conversion in inorganic-organic nanoreactors," Angew Chem Int Ed Engl, vol. 52, pp. 10349, 2013.

[66] K. Lourvanij and G.L. Rorrer, "Dehydration of glucose to organic acids in microporous pillared clay catalysts," Appl Catal A: Gen, vol. 109, pp. 147, 1994.

[67] L. Hu, Y. Sun, and L. Lin, "Efficient conversion of glucose into 5-hydroxymethylfurfural by chromium(III) chloride in inexpensive ionic liquid," Ind Eng Chem Res, vol. 51, pp. 1099, 2012.

[68] L. Hu, Y. Sun, L. Lin and S. Liu, "12-Tungstophosphoric acid/boric acid as synergetic catalysts for the conversion of glucose into 5-hydroxymethylfurfural in ionic liquid," Biomass Bioenergy, vol. 47, pp. 289, 2012.

[69] T. Stahlberg, S. Rodriguez-Rodriguez, P. Fristrup and A. Riisager, "Metal-free dehydration of glucose to 5(hydroxymethyl) furfural in ionic liquids with boric acid as a promoter," Chem An Eur J, vol. 17, pp. 1456, 2011.

[70] Q. Xu, Z. Zhu, Y. Tian, J. Deng, J. Shi and Y. Fu, "SnMCM-41 as efficient catalyst for the conversion of glucose into 5-hydroxymethylfurfural in ionic liquids," Bioresources, vol. 9, pp. 303, 2013.

[71] Z. Zhang, B. Liu and Z. Zhao, "Conversion of fructose into 5-HMF catalyzed by $\mathrm{GeCl}_{4}$ in $\mathrm{DMSO}$ and [BMIM]Cl system at room temperature," Carbohydr Polym, vol. 88, pp. $891,2012$.

[72] F. Ilgen, D. Ott, D. Kralisch, C. Reil, A. Palmberger and B. König, "Conversion of carbohydrates into 5hydroxymethylfurfural in highly concentrated low melting mixtures," Green Chem, vol. 11, pp. 1948, 2009.

[73] Y. Qu, C. Huang, J. Zhang and B. Chen, "Efficient dehydration of fructose to 5-hydroxymethylfurfural catalyzed by a recyclable sulfonated organic heteropolyacid salt," Bioresour Technol, vol. 106, pp. 170, 2012.

[74] Y. Roman-Leshkov, J.N. Chheda and J.A. Dumesic, "Phase modifiers promote efficient production of hydroxymethylfurfural from fructose," Science, vol. 312, pp. 1933, 2006.

[75] Y.H. Seo and J.I. Han, "Direct conversion from Jerusalem artichoke to hydroxymethylfurfural (HMF) using the Fenton reaction," Food Chem, vol. 151, pp. 207, 2014.

[76] A.S. Amarasekara, L.D. Williams and C.C. Ebede, "Mechanism of the dehydration of D-fructose to 5hydroxymethylfurfural in dimethyl sulfoxide at 150 degrees $C$ : an NMR study," Carbohydr Res, vol. 343, pp. 3021, 2008.

[77] X. Qi, M. Watanabe, T.M. Aida and R.L.J. Smith, "Selective conversion of D-fructose to 5hydroxymethylfurfural by ion-exchange resin in acetone/dimethyl sulfoxide solvent mixtures," Ind Eng Chem Res, vol. 47, pp. 9234, 2008.

[78] S.H. Mushrif, S. Caratzoulas and D.G. Vlachos, "Understanding solvent effects in the selective conversion of fructose to 5-hydroxymethyl-furfural: a molecular dynamics investigation," Phys Chem Chem Phys, vol. 14, pp. 2637, 2012. [79] M.J. Climent, A. Corma and S. Iborra, "Converting carbohydrates to bulk chemicals and fine chemicals over heterogeneous catalysts," Green Chem, vol. 13, pp. 520, 2011. [80] N. Shi, Q. Liu, Q. Zhang, T. Wang and L. Ma, "High yield production of 5-hydroxymethylfurfural from cellulose by high concentration of sulfates in biphasic system," Green Chem, vol. 15, pp. 1967, 2013.

[81] J.N. Chheda, Y. Román-Leshkov and J.A. Dumesic, "Production of 5- hydroxymethylfurfural and furfural by dehydration of biomass-derived mono- and poly-saccharides," Green Chem, vol. 9, pp. 342, 2007.

[82] M. Petkovic, K.R. Seddon, L.P. Rebelo and C. Silva Pereira, "Ionic liquids: a pathway to environmental acceptability," Chem Soc Rev, vol. 40, pp.1383, 2011.

[83] P. Wang, H. Yu, S. Zhan and S Wang, "Catalytic hydrolysis of lignocellulosic biomass into 5hydroxymethylfurfural in ionic liquid," Bioresour Technol, vol. 102, pp. 4179, 2011.

[84] Y.B. Yi, J.W. Lee, S.S. Hong, Y.H. Choi and C.H. Chung, "Acid mediated production of hydroxymethylfurfural from raw plant biomass with high inulin in an ionic liquid," $J$ Ind Eng Chem, vol. 17, pp. 6, 2011.

[85] Y.B. Yi, M.G. Ha, J.W. Lee, C.H. Chung, "New role of chromium fluoride: its catalytic action on the synthesis of hydroxymethylfurfural in ionic liquid using raw plant biomass and characterization of biomass hydrolysis," Chem Eng J, vol. 180, pp. 370, 2012.

[86] Y.B. Yi, M.G. Ha, J.W. Lee, S.M. Park, Y.H. Choi and C.H. Chung, "Direct conversion of citrus peel waste into hydroxymethylfurfural in ionic liquid by mediation of fluorinated metal catalysts," J Ind Eng Chem, vol. 19, pp. 523, 2013.

[87] H. Li and S. Yang, "Catalytic transformation of fructose and sucrose to HMF with proline-derived ionic liquids under mild conditions," Int J Chem Eng, vol. 2014, pp. 1, 2014.

[88] A.H. Jadhav, H. Kim and I.T. Hwang, "Efficient selective dehydration of fructose and sucrose into 5hydroxymethylfurfural (HMF) using dicationic room temperature ionic liquids as a catalyst," Catal Commun, vol. 21, pp. 96, 2012.

[89] S.V. Dzyuba, K.D. Kollar and S.S. Sabnis, "Synthesis of imidazolium room-temperature ionic liquids," J Chem Educ, vol. 86, pp. 856, 2009.

[90] M. Deetlefs and K.R. Seddon, "Assessing the greenness of some typical laboratory ionic liquid preparations," Green Chem, vol. 12, pp.17, 2010.

[91] N.V. Plechkova and K.R. Seddon, "Applications of ionic liquids in the chemical industry," Chem Soc Rev, vol. 37, pp. 123, 2008.

[92] P. Pollet, E.A. Davey, E.E. Ureňa-Benavides, C.A. Eckert and C.L. Liotta, "Solvents for sustainable chemical processes," Green Chem, vol. 16, pp. 1034, 2014.

[93] M. Uerdingen, C. Treber, M. Balser, G. Schmitt and C. Werner, "Corrosion behaviour of ionic liquids," Green Chem, vol. 7, pp. 321, 2005.

[94] F. Endres, D. MacFarlane and A. Abbott, "Synthesis of ionic liquids. Electrodeposition from ionic liquids," John Wiley \& Sons, pp. 20, 2008.

[95] M. Freemantle, "Properties of ionic liquids," $A n$ introduction to ionic liquids. Royal Society of Chemistry, pp. $38,2010$. 
[96] J.S. Yadav, B.V.S. Reddy and K. Premalatha, "1-Butyl-3methylimidazolium tetrafluoroborate $\left([\mathrm{BMIM}] \mathrm{BF}_{4}\right)$ ionic liquid: a novel and recyclable reaction medium for the synthesis of vic-diamines," Adv Synth Catal, vol. 345, pp. 948, 2003.

[97] Y. Su, H.M. Brown, X. Huang, X-d. Zhou, J.E. Amonette and Z.C. Zhang, "Single-step conversion of cellulose to 5hydroxymethylfurfural (HMF), a versatile platform chemical," Appl Catal A: Gen, vol. 361, pp. 117, 2009.

[98] S. Hu, Z. Zhang, J. Song, Y. Zhou and B. Han, "Efficient conversion of glucose into 5-hydroxymethylfurfural catalyzed by a common Lewis acid $\mathrm{SnCl}_{4}$ in an ionic liquid," Green Chem, vol. 11, pp. 1746, 2009.

[99] S. Lima, P. Neves, M.M. Antunes, M. Pillinger, N. Ignatyev and A.A. Valente, "Conversion of mono/di/polysaccharides into furan compounds using 1-alkyl3-methylimidazolium ionic liquids," Appl Catal A: Gen, vol. 363, pp. 93, 2009.

[100] Z. Wei, Y. Liu, D. Thushara and Q. Ren, "Entrainerintensified vacuum reactive distillation process for the separation of 5-hydroxylmethylfurfural from the dehydration of carbohydrates catalyzed by a metal salt-ionic liquid," Green Chem, vol. 14, pp. 1220, 2012.

[101] M. Möller, F. Harnisch and U. Schröder, "Microwaveassisted hydrothermal degradation of fructose and glucose in subcritical water," Biomass Bioenergy, vol. 39, pp. 389, 2012.

[102] P. Carniti, A. Gervasini, S. Biella and A. Auroux, "Niobic acid and niobium phosphate as highly acidic viable catalysts in aqueous medium: fructose dehydration reaction," Catal Today, vol. 118, pp. 373, 2006.

[103] J.B. Binder and R.T. Raines, "Simple chemical transformation of lignocellulosic biomass into furans for fuels and chemicals," J Am Chem Soc, vol. 131, pp. 1979, 2009.

[104] J.B. Binder, A.V. Cefali, J.J. Blank and R.T. Raines, "Mechanistic insights on the conversion of sugars into 5hydroxymethylfurfural," Energy Environ Sci, vol. 3, pp. 765 , 2010.

[105] C.J. Moye and R.J. Goldsack, "Reaction of ketohexoses with acid in certain non-aqueous sugar solvents," J Appl Chem, vol. 16, pp. 206, 1966.

[106] P. Bhaumik and P.L. Dhepe, "Influence of properties of SAPO's on the one-pot conversion of mono-, di- and polysaccharides into 5-hydroxymethylfurfural," $R S C A d v$, vol. 3, pp. 17156, 2013.

[107] H. Zhao, J.E. Holladay, H. Brown and Z.C. Zhang, "Metal chlorides in ionic liquid solvents convert sugars to 5hydroxymethylfurfural," Science, vol. 316, pp. 1597, 2007.

[108] Z.D. Ding, J.C. Shi, J.J. Xiao, W.X. Gu, C.G. Zheng and H.J. Wang, "Catalytic conversion of cellulose to 5hydroxymethyl furfural using acidic ionic liquids and cocatalyst," Carbohydr Polym, vol. 90, pp. 792, 2012.

[109] T. Stahlberg, M.G. Sorensen and A. Riisager, "Direct conversion of glucose to 5-(hydroxymethyl)furfural in ionic liquids with lanthanide catalysts," Green Chem, vol. 12, pp. $321,2010$.

[110] Q, Cao, X. Guo, S. Yao, J. Guan, X. Wang, X. Mu, et al. "Conversion of hexose into 5-hydroxymethylfurfural in imidazolium ionic liquids with and without a catalyst," Carbohydr Res, vol. 346, pp. 956, 2011.

[111] M. Chidambaram and A.T. Bell, "A two-step approach for the catalytic conversion of glucose to 2,5-dimethylfuran in ionic liquids," Green Chem, vol. 12, pp. 1253, 2010.

[112] S.P. Chundawat, B. Venkatesh and B.E. Dale, "Effect of particle size based separation of milled corn stover on AFEX pretreatment and enzymatic digestibility," Biotechnol Bioeng, vol. 96, pp. 219, 2007.
[113] A.C.Cope, United States patent 2,917,520. In: Office USPaT; United States of America, 1959.

[114] R.J. van Putten, A.S. Dias and E. de Jong, "Furan-based building blocks from carbohydrates," In: Imhof P, van der Waal JC, editors. Catalytic process development for renewable materials. Wiley, pp. 81, 2013.

[115] G. Fléche, A. Gaset, J.P. Gorrichon, E. Truchot and P. Sicard, United States patent 4,339,387. In: Office USPaT. United States of America: Roquette Freres, 1982.

[116] C. Bazoa, F. Raymond, L. Rigal and A. Gaset, French patent FR2669635. In: (INPI) INdlPI. France: Furchim, 1990.

[117] R. Gedye, F. Smith, K. Westaway, H. Ali, L. Baldisera, L. Laberge, et al. "The use of microwave ovens for rapid organic synthesis," Tetrahedron Lett, vol. 27, pp. 279, 1986.

[118] R.J. Giguere, T.L. Bray and S.M. Duncan, "Application of commercial microwave ovens to organic synthesis," Tetrahedron Lett, vol. 27, pp. 4945, 1986.

[119] C.O. Kappe, "Controlled microwave heating in modern organic synthesis," Angew Chem Int Ed Engl, vol. 43, pp. 6250, 2004.

[120] A. de la Hoz, A. Diaz-Ortiz and A. Moreno, "Microwaves in organic synthesis. Thermal and non-thermal microwave effects," Chem Soc Rev, vol. 34, pp. 164, 2005.

[121] M. Nüchter, U. Müller, B. Ondruschka, A. Tied and W. Lautenschläger, "Microwave-assisted chemical reactions," Chem Eng Technol, vol. 26, pp. 1207, 2003.

[122] M. Grannow, R. White, J. Clark and D. Macquarrie, "Energy efficiency in chemical reactions: a comparative study of different reaction techniques," Org Process Res Dev, vol. 9, pp. 516, 2005 .

[123] M. Nüchter, B. Ondruschka, W. Bonrath and A. Gum, "Microwave assisted synthesis - a critical technology overview," Green Chem, vol. 6, pp. 128, 2004.

[124] C. Li, Z. Zhang and Z.K. Zhao, "Direct conversion of glucose and cellulose to 5-hydroxymethylfurfural in ionic liquid under microwave irradiation," Tetrahedron Lett, vol. 50, pp. 5403, 2009.

[125] Z. Zhang and Z.K. Zhao, "Microwave-assisted conversion of lignocellulosic biomass into furans in ionic liquid," Bioresour Technol, vol. 101, pp. 1111, 2010.

[126] B. Liu, Z. Zhang and Z.K. Zhao, "Microwave-assisted catalytic conversion of cellulose into 5-hydroxymethylfurfural in ionic liquids," Chem Eng J, vol. 215, pp. 517, 2013.

[127] S. De, S. Dutta and B. Saha, "Microwave assisted conversion of carbohydrates and biopolymers to 5hydroxymethylfurfural with aluminium chloride catalyst in water," Green Chem, vol. 13, pp. 2859, 2011.

[128] M. Imteyaz Alam, S. De, S. Dutta and B. Saha, "Solidacid and ionic liquid catalyzed one-pot transformation of biorenewable substrates into a platform chemical and a promising biofuel," RSC Adv, vol. 2 pp. 6890, 2012.

[129] X. Qi, M. Watanabe, T.M. Aida and J.R.L. Smith, "Catalytic dehydration of fructose into 5hydroxymethylfurfural by ion-exchange resin in mixedaqueous system by microwave heating," Green Chem, vol. 10, pp. 799, 2008. 